\author{
O ENSINO DA HISTÓRIA SOB O FAROL AMBIEN- \\ TALISTA: UM DESAFIO DE SE COMBATER PARA- \\ DIGMAS RELACIONADOS A HISTÓRIA AMBIEN- \\ TAL E SUA APLICAÇÃO NO MEIO EDUCACIONAL
}

\title{
THE TEACHING OF HISTORY UNDER THE ENVI- RONMENTAL LIGHTHOUSE: A CHALLENGE IN \\ FIGHTING PARADIGMS RELATED TO ENVIRON- MENTAL HISTORY AND ITS APPLICATION IN THE EDUCATIONAL ENVIRONMENT
}

Diego Fernando da Silva ${ }^{1}$

Resumo: O presente artigo tem a finalidade de fomentar o debate entre concepções e confluências do ensino da História geral e teorias pedagógicas na parte ambiental, não se esquecendo da formação dos educandos, e da prática docente. Dessa maneira, a metodologia para a elaboração desse artigo parte de leituras da historiografia sobre as suas preocupações acerca da temática ambientalista e seus fatores fundamentais. Percebemos que, a pesquisa, aponta a necessidade de uma mudança de postura de todos os envolvidos na sociedade e não apenas no ambiente escolar. Daí a importância de se evidenciar claramente os significados dos conceitos de Ensino de História, Educação Ambiental e um modo que se possa direcionar e apontar novos caminhos e no-

1 Universidade Regional do Cariri URCA

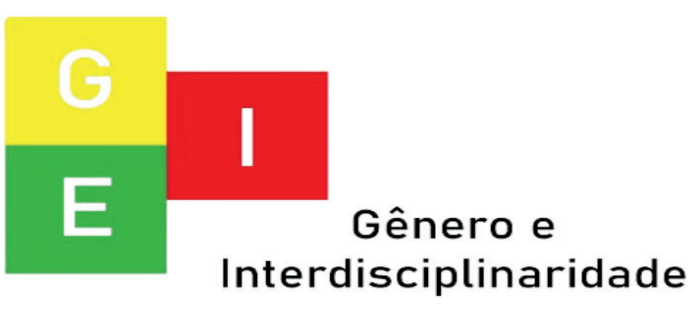


ISSN: $2675-7451$

Vol. 02 - n 02 - ano 2021

Editora Acadêmica Periodicojs

vas práticas.

Palavras chaves: Ensino de História. História Ambiental. Aprendizagem significativa. Formação docente.

Abstract: His article aims to foster the debate between conceptions and confluences in the teaching of general history and pedagogical theories in the environmental area, not forgetting the training of students and teaching practice. Thus, the methodology for the elaboration of this article starts from readings of the historiography about his concerns about the environmental theme and its fundamental factors. We realized that the research points to the need for a change in the attitude of everyone involved in society and not Just in the school environment. Hence the importance of clearly evidencing the meanings of the concepts of teaching History, Environmental Education and a way that can be directed and pointed to new paths and new practices.

Keywords: History teaching. Environmental History. Meaningful learning. Teacher training.

\section{INTRODUÇÃO}

Vivemos em uma sociedade marcada pelas transformações no processo de ensino e aprendizagem, onde o conhecimento e o acesso a novas metodologias pelos profissionais da educação são primordiais para a obtenção do sucesso na sua profissão, e para que sejamos inseridos na contemporaneidade em que o corpo social se transformou, seja na escola ou na comunidade em geral. Logo, podemos notar que o uso de diferentes me-

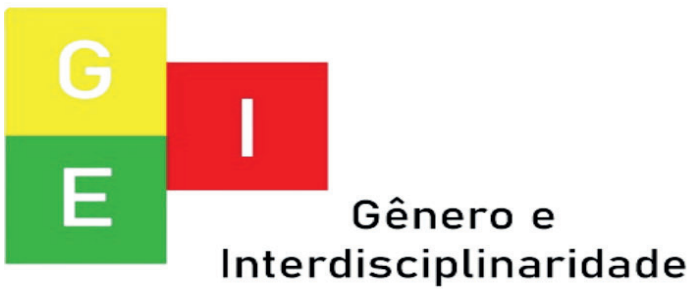


todologias no ensino de História tem sido amplamente discutido, como forma de auxiliar a reorganizar em nosso cotidiano formas mais críticas de conviver e refletir sobre a nossa própria realidade.

Nesse sentido, o objetivo desse artigo é fomentar o debate entre concepções de História e das Teorias Ambientais que compõem a formação docente e dos educandos, que infelizmente ainda é pouco trabalhada. Assim, também, pensando a Educação Histórica como possibilidade de uma aprendizagem autônoma e significativa.

Dessa maneira, partimos da premissa que há uma relação necessária entre as concepções teórico-históricas, ambientalistas, aprendizagem do aluno e a prática docente em sala de aula. Para refletir o entrelaçamento das concepções históricas e pedagógicas do meio ambiente no processo de formação na prática educacional e cotidiana, partimos das seguintes indagações: como se encontra o ensino de História no Brasil? como os professores estão trabalhando a educação ambiental nas escolas? o que é História ambiental? e qual a problemática encontrada na Educação Ambiental na escola? É nessa perspectiva que promoveremos essa discussão. Assim, cabe a análise acerca das causas, consequências e possível solução do problema. Vale salientar, que a educação é o melhor meio estrutural, político e econômico para o desenvolvimento do nosso país.

\section{DILEMAS ENFRENTADOS NO ENSINO DE HISTÓRIA \\ Nos últimos anos, a} questão do ensino de História, tem sido muito discutida no Bra-

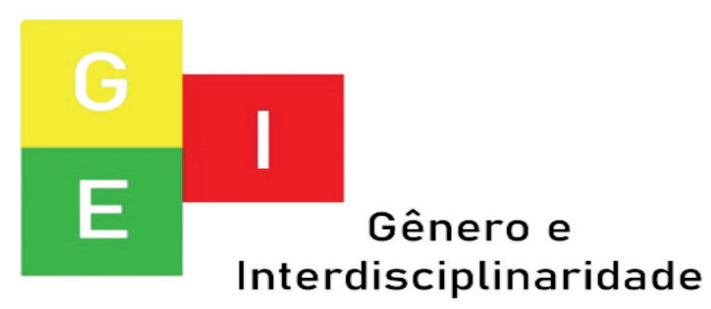


ISSN: 2675-7451

Vol. 02 - n 02 - ano 2021

Editora Acadêmica Periodicojs

sil. Assim sendo, torna-se uma

temática muito significativa, pois

envolve múltiplos fatores, entre

Seguindo essa linha eles, os culturais, políticos, econômicos, psicossociais e étnicos. Lamentavelmente o número de reportagens em jornais e nas mídias gerais sobre esse assunto ainda é muito raro. Diante disso, torna-se fundamental a discussão dos variados aspectos que envolvem o ensino de História, a fim do pleno funcionamento da sociedade. A partir disso somos levados à necessidade de refletir criticamente sobre a afirmação de Alessandro Portelli:

[...] as nossas mentes não refletem diretamente a realidade. Só percebemos o mundo através de uma estrutura de convenções, esquemas e estereótipos, um entrelaçamento que varia de uma cultura para outra. (BURKE, 1992,

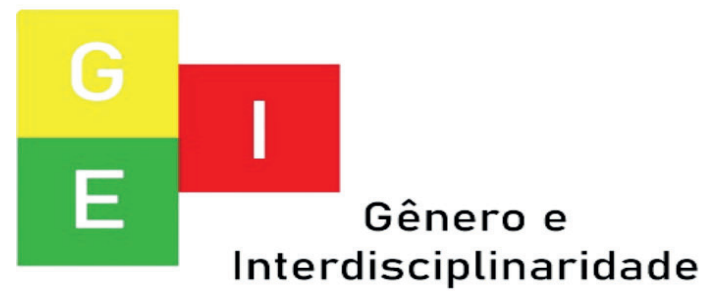
cepções do processo de ensino e aprendizagem denominadas tendências educacionais: tradicional, transformadora e a histórico-crítica; a terceira é a prática docente propriamente dita, ou seja, a sala de aula a partir da perspectiva da educação histórica.

Diante dos aspectos ci- 
ISSN: 2675-745

Vol. 02 - n 02 - ano 202

Editora Acadêmica Periodicoj

tados, observa-se que todos estão intrinsecamente ligados aos protagonistas das instituições de ensino, ou seja, os educandos. Assim pensamos a formação sustentada nesse tripé de princípios teóricos e metodológicos para possibilitar um melhor entendimento para todos e estabelecer a relação entre os elementos essenciais do processo de ensino e aprendizagem da disciplina abordada que são: as relações entre os educadores, educandos e a sociedade em relação ao meio em que vivem e atuam. Assim, como todas as áreas do conhecimento os objetivos, conteúdos e as metodologias de ensino complementam esses fatores. Logo, não podem ser desconsideradas. Portanto, a prática pedagógica deve caracterizar-se pela consideração das diversas manifestações culturais carregadas de símbolos, consciência e de códigos que expressam marcas peculiares de cada grupo sociocultural. Além disso, podemos mencionar que Márcio Rogério afirma:

$$
\begin{aligned}
& \text { No campo da His- } \\
& \text { tória, a questão do } \\
& \text { ponto de vista é fun- } \\
& \text { damental e está no } \\
& \text { centro de uma série } \\
& \text { de debates. No ensi- } \\
& \text { no, tanto de história, } \\
& \text { como de outras dis- } \\
& \text { ciplinas, reconhecer } \\
& \text { e respeitar pontos de } \\
& \text { vista é uma habili- } \\
& \text { dade a ser desenvol- } \\
& \text { vida. Dessa maneira, } \\
& \text { chegando ao respei- } \\
& \text { to. (CANO, 2012, } \\
& \text { p.115) }
\end{aligned}
$$

Partindo dessa premissa, a educação histórica, fundamenta-se na ideia de que o homem age propositalmente sobre a realidade para poder viver. $\mathrm{O}$ ser humano produz para si e para o gênero humano por meio da atividade do trabalho, que o define

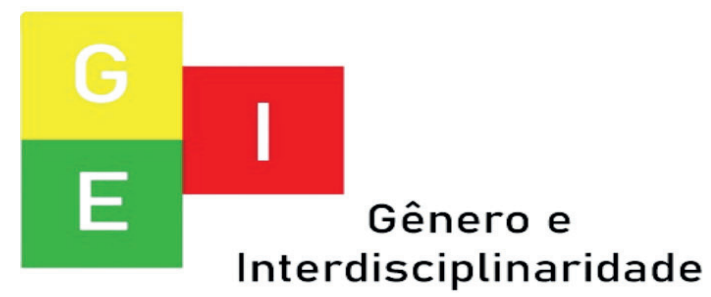


ISSN: 2675-7451

Vol. 02 - n 02 - ano 2021

Editora Acadêmica Periodicojs

e o caracteriza enquanto ser social histórico. Assim, a consciência histórica é o modo pelo qual a relação entre a experiência no espaço e a intenção no tempo se realiza no processo da vida humana. Destacam-se dois aspectos provocantes que é o trabalho intelectual realizado pelo homem para tornar suas intenções de agir conforme a experiência do tempo vivenciado. Para isso, outras construções intelectuais precisam ser aperfeiçoadas, tais como a visão crítica do que está tencionado nas condições e circunstâncias da vida. Nesse sentido, a interpretação é tida com um exemplo histórico, as pessoas podem até ter oportunidades igualitárias, mas estão obrigados a condições e circunstâncias desiguais, injustas e violentas.

A minha opinião, no decorrer do processo, foi mudando, bastan- te. Porque uma coisa é a ideia que você tem através dos livros, através de um contato pessoal. Porque Prestes é o grande mito da esquerda da nossa história. E é claro que isso exercia em mim um fascínio. Á medida em que você vai entrando na história do personagem, aprofundando, verticalizando-a, obviamente você vai descobrindo o lado humano dele. (DE OLIVEIRA, ALMEIDA; FONSECA, 2008, p. 79)

Uma das grandes reclamações que os professores de História, fazem e ouvem dos colegas de trabalho é a falta de motivação que grande parcela dos alunos demonstra nas aulas da disciplina. Considerando esse contexto, alguns temas como: Egito, a educação espartana, as

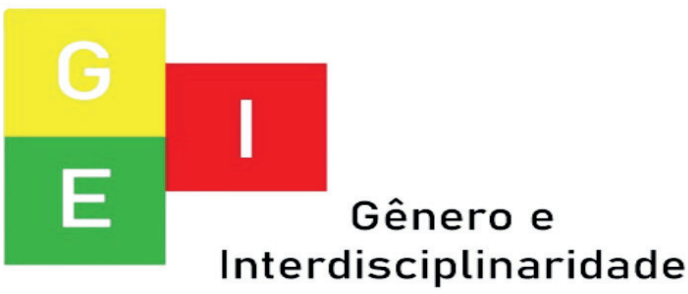


batalhas medievais, os grandes inventos da renascença, a renascença, as guerras e revoltas dos séculos passados trazem consigo alguns alentos às metas dos educadores, pois encontram grandes temáticas, e consequentemente, uma plateia interessada e curiosa. Assim sendo, é surpreendente como os alunos se dedicam a temas fantasiosos e mitológicos e, especificamente, entre os meninos, conteúdos que envolvem batalhas. A utilização de recursos didáticos como slide, músicas, roda de conversa, circuito, mapa conceitual e textos que explorem o aprofundamento do conteúdo estudado. Portanto, vê-se que existem alguns conteúdos mais atrativos e mesmo aqueles que não são, se a metodologia condizer com a prática no ensino, haverá um aprendizado constante e promissor. Dessa maneira, as instituições de ensino irão for- mar cidadãos preparados para o mercado de trabalho e sua socialização, já que a História é antes de tudo, social.

\section{HISTÓRIA AMBIENTAL, PARA QUE E PARA QUEM?} Por muito tempo houve um distanciamento enorme entre cultura e natureza. Logo, o mesmo influenciou de maneira significativa as relações do homem e como ele se diferenciava dessa natureza que era sua contraposição. Ou seja, automaticamente foi se instalando vários paradigmas negativos a respeito da História Ambiental que inclusive está intrinsecamente ligada a contemporaneidade, especificamente nos meios de ensino onde muitas questões são abordadas sem o provimento de novos pensamentos e abordagens. É expressivo o número de pessoas

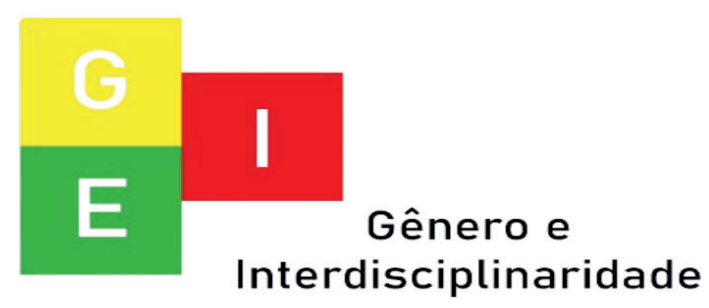


ISSN: 2675-7451

Vol. 02 - n 02 - ano 2021

Editora Acadêmica Periodicojs

que não sabem nem do que se trata a História Ambiental e qual o seu papel na sociedade. Seguindo essa linha de raciocínio podemos refletir sobre o comentário de Paulo Henrique Martinez:

As questões ambientais despontam com grande força na atualidade e incidem imediata e diretamente no trabalho realizado por historiadores na pesquisa, no ensino e na apreciação crítica da sociedade brasileira. Um novo questionamento sobre os modos de vida humana e sua reordenação, nesse início de século, sugere também a busca de novos métodos e abordagens na investigação histórica. (MARTINEZ, 2001, p. 218)

Acerca do que foi mencionado pode-se afirmar que o meio ambiente possui total relação com os seres humanos, apesar das atitudes de superioridade sobre o domínio da natureza que os mesmos praticam, não respeitando a biodiversidade. Além disso, observa-se que a divisão abstrata entre sociedade e natureza responde a necessidade de afirmação do ser humano perante o mundo de seus semelhantes, valorizando atitudes antropocêntricas, como a consciência e racionalidade. Um exemplo disso são as recentes transformações no meio ambiente, como os impactos das ações humanas. Nesse sentido, essa limitação que colocam sobre a temática, está totalmente equivocada e parte principalmente de pessoas que possuem uma visão capitalista e egocêntrica.

Sob outro ângulo é possível ainda avaliar a resiliência do problema. Dessa forma, podemos

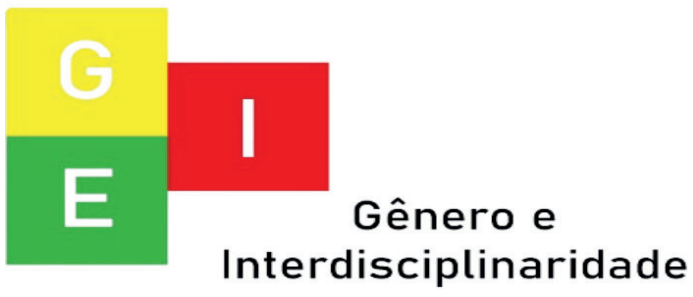


ISSN: 2675-745

Vol. 02 - n 02 - ano 202

Editora Acadêmica Periodicoj

analisar algumas indagações do escritor e historiador José Augusto Drummond:

Vale lembrar que, a esta altura do debate cientifico, nem a história ambiental nem outras disciplinas sociais que vêm incorporando elementos do mundo natural a sua lista de variáveis analíticas propõem um determinismo unilateral. A cultura humana age sobre o meio físico-material, propiciando significados e usos complexos dos seus elementos. Evito, por isso, entrar pela bolorenta discussão sobre o determinismo. (DRUMMOND, 1991, p. 4)

Primordialmente, as ciências humanas, foram muito limitadas. Passando por vários desafios no passado e que ainda enfrentam no presente. $\mathrm{O}$ mundo não pode prescindir daqueles que o interpretam. A História, embora reunindo teses em sua maioria aparentemente abstratas, jogou um papel decisivo na construção da aventura humana. Propiciando ao mundo um melhor entendimento dos diversos fatores, mesmo o homem achando muitas vezes dono de poderes absolutos. Aos humanistas sobrou a missão salvadora de libertar enormidades dos seus equívocos. Fora as mesmas que desconstruíram dogmas e deram luzes aos caminhos da História humana e natural.

Foram eles que decifraram, ao longo dos séculos, os grandes enigmas da existência. A humanidade muito deve a estes indivíduos que fazem uso da inteligência para enfrentar $o$ desafio máximo da espécie, que é a possível compreensão do

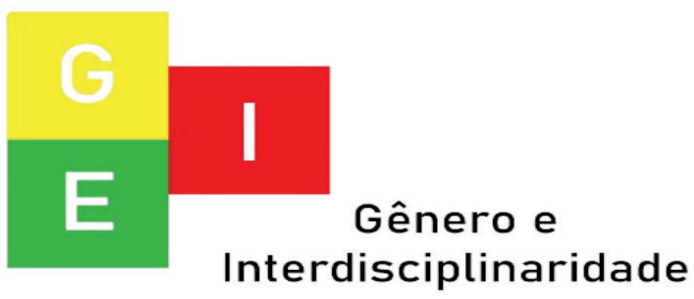


ISSN: 2675-7451

Vol. 02 - n 02 - ano 2021

Editora Acadêmica Periodicojs

mundo e a destruição da arrogância. Desse modo, os sujeitos não estão preparados para assumir papéis emancipadores na sociedade. Apesar dos seres humanos agirem com imprudência e irresponsabilidade com o seu próprio lugar, podemos chegar à conclusão que o homem possui sim relação com a natureza, ou melhor, ele faz parte dela. Se as pessoas continuarem destruindo o ambiente natural, vão acabar se destruindo também.

E o interessante é que as ciências humanas não se importam com determinismos, porque abre espaço justamente para refletir e pensar. Agindo totalmente contra a famosa visão moderna. Assim sendo, a História é um agente ativo na parte ambiental, compreendendo e analisando as formas de como a sociedade se organiza e se reorganizam.

\section{DESAFIOS PARA A VIABI- LIZAÇÃO DA EDUCAÇÃO AMBIENTAL}

Atualmente, torna-se importante salientarmos que utilizar metodologias associadas ao meio ambiente nas aulas de História e outras disciplinas das ciências humanas enquanto proposta de ensino e aprendizagem, tem se tornado fundamental para que os educandos possam adquirir diversos conhecimentos, chegando a perceberem a importância do uso da criticidade em suas relações com a sociedade e a natureza. Assim, é perceptível que o primeiro passo é sair do tradicionalismo.

Paulo Freire denomina a tendência tradicional de "educação bancária" e afirma:

Nela o educador apa-

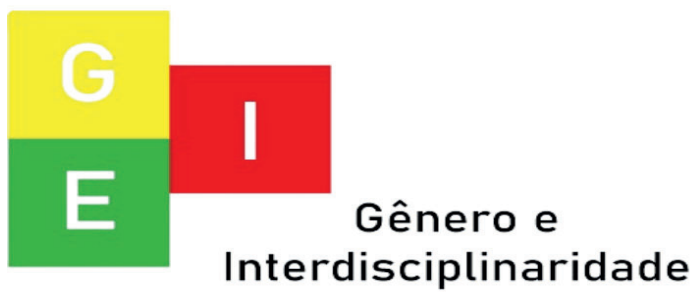


rece como seu indiscutível agente, como o seu real sujeito, cuja tarefa indeclinável é 'encher' os educandos dos conteúdos de sua narração. Conteúdos que são retalhos da realidade desconectados da totalidade em que se engendram e em cuja visão ganhariam significação. (FREIRE,1996, p.103)

Tendo em vista, a reflexão feita pelo autor, percebe-se que as escolas como um todo devem criar e promover estratégias que despertem o interesse dos alunos em querer aprender os conteúdos da História Ambiental, ao mesmo tempo em que se aproximem com sua própria realidade. Vale ressaltar que, todo lugar conta com uma diversidade natural muito rica, mesmo diante de todo desmatamento humano, como por exemplo, reservas de calcários, matas, rios e trilhas.

A partir disso, vê-se que podemos chegar a metas que pareciam ser inalcançáveis. Nesse sentido, é com esse intuito que a Política Nacional de Educação Ambiental (LEI No 9.795, DE 27 DE ABRIL DE 1999.), afirma:

Art. 1o Entendem-se por educação ambiental os processos por meio dos quais o indivíduo e a coletividade constroem valores sociais, conhecimentos, habilidades, atitudes e competências voltadas para a conservação do meio ambiente, bem de uso comum do povo, essencial à sadia qualidade de vida e sua sustentabilidade. (BRASIL, 1999, p.1)

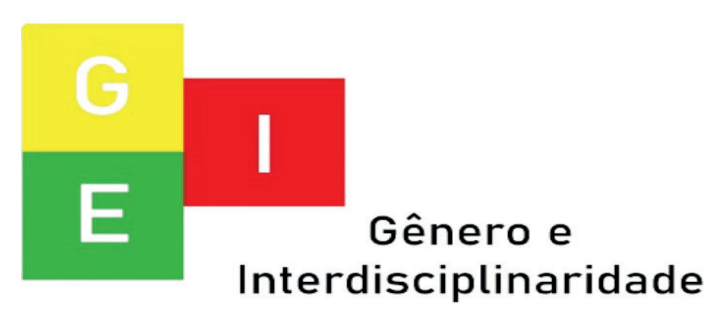


ISSN: 2675-7451

Vol. 02 - n 02 - ano 2021

Editora Acadêmica Periodicojs

E, ainda, complementa

que,

Art. 2o A educação ambiental é um componente essencial e permanente da educação nacional, devendo estar presente, de forma articulada, em todos os níveis modalidades do processo educativo, em caráter formal e não-formal. (BRASIL, 1999, p.1)

Portanto, a educação ambiental mostrou-se ser um mecanismo inovador e modificador, visando melhorias entre o homem e o meio natural. Proporcionando assim, reflexões sobre meio ambiente, sustentabilidade, preservação e conservação. São destacados temas como o consumo exagerado de recursos naturais, crise ambiental, efeito estu- fa, tipos de lixo, coleta seletiva, reciclagem, relação do homem e natureza dentre outros. Todos são propostos para serem trabalhados com os alunos para que eles se familiarizem com as práticas sustentáveis e possam vislumbrar os problemas relacionados com a degradação do meio ambiente e suas implicações futuras.

Desse modo, ela busca seres mais reflexivos e críticos. Por conseguinte, o espaço escolar se torna um local adequado e indispensável gerador de conhecimentos acerca do meio ambiente para fins de cooperação e conservação de toda a população.

\section{CONSIDERAÇÕES FINAIS}

Diante do que foi refletido, concluiu-se que a preocupação com o meio ambiente cresceu principalmente nas últimas décadas, haja vista as intensas

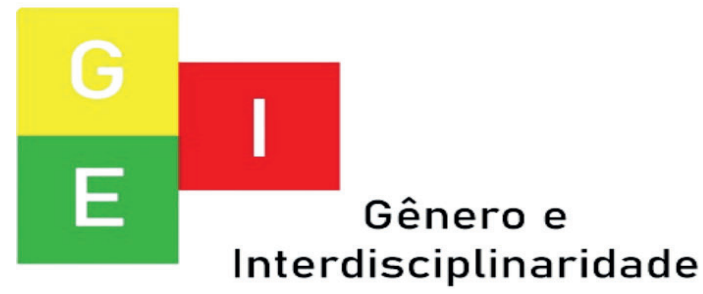


ISSN: 2675-745

Vol. 02 - n 02 - ano 202

Editora Acadêmica Periodicoj

transformações ambientais que o planeta terra está passando, associados sobretudo a interferência dos seres humanos sobre a natureza. Assim, o ensino da História Ambiental possibilita aos alunos os recursos metodológicos necessários à produção e compreensão do conhecimento e de como o mesmo é produzido.

É a partir desse confronto entre o homem e a natureza que se perpetua na contemporaneidade, que se torna possível aos educandos elaborar outros conhecimentos com argumentos próprios e critérios de seleção, construindo uma aprendizagem significativa e autônoma, transformando informações em conhecimentos e apropriando-se das ideias de forma mais concreta.

Tendo em vista, a importância de se refletir sobre as questões ambientais, em virtude das constantes transformações que

o planeta vem sendo submetido, faz-se necessário o engajamento do professor para a correta articulação dos conteúdos conceituais, procedimentais e atitudinais, ou seja, o que os alunos devem saber, fazer e ser. Dessa forma, trazendo à tona ideias relevantes e contemporâneas, visando obter sucesso em suas práticas e projetos pedagógicos.

\section{REFERÊNCIAS}

BRASIL. Lei da Educação Ambiental. Presidência da República Brasil. Brasília, DF: Senado Federal: Centro gráfico, 1999. Disponível em: http://www.planalto. gov.br/ccivil_03/leis/19795.htm. Acessado em: 03. fev. 2020.

BURKE, P. A escrita da história. Novas perspectivas, São Paulo: Editora da Unesp, 1992.

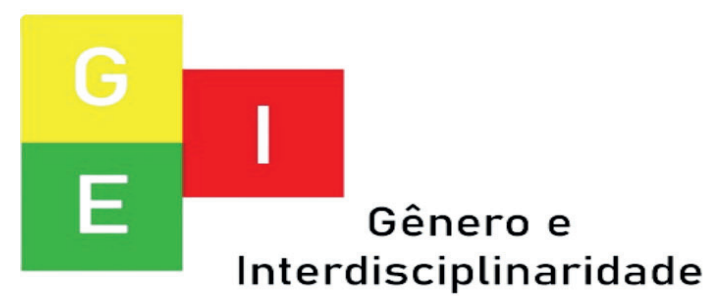


e a prática em História. 2012, p. 115

DE OLIVEIRA, R. S.; ALMEIDA, V. L.; FONSECA, V. A. História: A reflexão e a Prática de Ensino. Blucher, Ministério da Educação, 2008, p. 155

DRUMMOND, J. A. A História Ambiental: temas, fontes e linhas de pesquisa. Estudos históricos, Rio de Janeiro, vol. 4, n. 8, 1991, p. $177-197$

FREIRE, P. Pedagogia da Autonomia. $53^{\circ}$ ed. Rio de Janeiro: Paz e terra, 1996, 143p.

MARTINEZ, P. H. História e Meio Ambiente: Considerações sobre a Formação Continuada

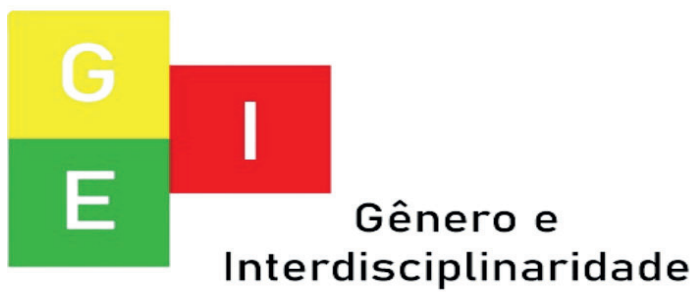

